\title{
Optimising pain management in children with acute otitis media through a primary care-based multifaceted educational intervention: study protocol for a cluster randomised controlled trial
}

Rick T. van Uum ${ }^{1 *}$ (D), Roderick P. Venekamp', Alies Sjoukes', Alma C. van de Pol', G. Ardine de Wit ${ }^{1,2}$, Anne G. M. Schilder ${ }^{1,3}$ and Roger A. M. J. Damoiseaux ${ }^{1}$

\begin{abstract}
Background: Whilst current guidelines highlight the importance of pain management for children with acute otitis media (AOM), there is evidence to suggest that this is not implemented in everyday practice. We have developed a primary care-based multifaceted educational intervention to optimise pain management in children with AOM, and we trial its clinical and cost effectiveness.

Methods: This cluster randomised controlled trial aims to recruit 250 children aged 6 months to 10 years presenting with AOM to general practitioners (GPs) in 30 primary care centres (PCCs) across the Netherlands. GPs in the PCCs allocated to the intervention group receive a blended GP educational programme (online and face-toface training). The intervention asks GPs to proactively discuss pain management with parents using an information leaflet, and to prescribe paracetamol and ibuprofen according to current guidelines. GPs in both groups complete an online module illustrating various otoscopic images to standardise AOM diagnosis. GPs in the PCCs allocated to the control group do not receive any further training and provide 'care as usual'.

During the 4-week follow-up, parents complete a symptom diary. The primary outcome is the difference in parent-reported mean earache scores over the first 3 days. Secondary outcomes include both number of days with earache and fever, GP re-consultations for AOM, antibiotic prescriptions, and costs. Analysis will be by intention-to-treat.
\end{abstract}

Discussion: The optimal use of analgesics through the multifaceted intervention may provide symptom relief and thereby reduce re-consultations and antibiotic prescriptions in children with AOM.

Trial registration: Netherlands Trial Register, NTR4920. Registered on 19 December 2014.

Keywords: Acute otitis media, Pain management, Analgesics, Multifaceted intervention, Primary care, RCT

\footnotetext{
* Correspondence: r.t.vanuum-2@umcutrecht.nl

1 Julius Center for Health Sciences and Primary Care, University Medical

Center Utrecht, Utrecht University, Stratenum 5.143, PO Box 85500, 3508, GA,

Utrecht, The Netherlands

Full list of author information is available at the end of the article
}

(C) The Author(s). 2018 Open Access This article is distributed under the terms of the Creative Commons Attribution 4.0 International License (http://creativecommons.org/licenses/by/4.0/), which permits unrestricted use, distribution, and reproduction in any medium, provided you give appropriate credit to the original author(s) and the source, provide a link to the Creative Commons license, and indicate if changes were made. The Creative Commons Public Domain Dedication waiver (http://creativecommons.org/publicdomain/zero/1.0/) applies to the data made available in this article, unless otherwise stated. 


\section{Background}

Analgesics are the cornerstone of childhood acute otitis media (AOM) management. Optimal use of analgesics provides symptom relief and has the potential to reduce re-consultations, antibiotic prescription, and healthcare costs. Current AOM practice guidelines therefore emphasise the importance of providing analgesics to all children with $\mathrm{AOM}$ in an weight-appropriate dose, in addition to prescribing antibiotics for certain children $[1,2]$.

In daily practice, little attention is paid to earache management during the medical consultation [3-6] and routine antibiotic prescription is still very common $[3,7,8]$. Key factors driving the management decisions of general practitioners (GPs) include concerns from both clinicians and parents about the vulnerability of young children and parental pressure to prescribe antibiotics; parents believe that antibiotics are the proper treatment for AOM and analgesics as a standalone treatment are generally considered insufficient [9-11].

Multifaceted interventions addressing these concerns from both the GP and parent perspective have proven effective in changing clinical practice $[12,13]$ and are highly valued by GPs [14]. We therefore developed a primary care-based multifaceted educational intervention to optimise pain management in children with AOM and we will trial its clinical and cost effectiveness.

\section{Objective}

We aim to establish the clinical and cost effectiveness of a primary care-based multifaceted educational intervention focused on optimising pain management in children with AOM.

\section{Methods and analysis}

\section{Design of the intervention to optimise pain management} in children with AOM

The Medical Research Council guidance for complex interventions was used to develop our multifaceted intervention [15]. The various elements of the intervention were chosen based on a literature review, consultation with clinical experts including a broad range of disciplines such as GPs, an ear, nose, and throat (ENT) surgeon, and a nurse specialist as well as educational experts, and a qualitative pre-study with GPs and parents.

Following this multi-phase process, we found that multifaceted interventions including a GP educational programme with condensed information of a clinical guideline may impact GP prescribing [12, 13, 16, 17], and allows for addressing parental factors influencing the management decisions of GPs $[6,11]$. Individual online training appeared to be more effective than face-to-face group work [18], and the impact may increase when online training is complemented by individual face-to-face visits to convey feedback on performance in the training and to overcome obstacles to change [19]. In addition, patient information leaflets have the potential to impact GP prescribing and guide parental management decisions [20, 21].

Our multifaceted intervention therefore comprises of four core elements to educate GPs in different aspects (knowledge, attitude, skills, and behaviour): i) an online training module; ii) a face-to-face-meeting; iii) a parent information leaflet; and iv) prescription of analgesics (see Table 1).

\section{Online training module}

The online training module, which takes approximately 30 min to complete, educates GPs about pain management in childhood AOM through a combination of proven effective educational components such as case-based learning [22], self-assessment with immediate feedback [22], reflection [22], and video demonstrations of effective communication techniques [13, 23]. GPs are trained to proactively discuss pain management with parents using the parent information leaflet and they are prompted to prescribe both paracetamol and ibuprofen according to current AOM guidelines [1, 24].

GP adherence to the online training module (i.e. whether the GP completed the module), as well as individual answers by GPs to the various questions, will be automatically recorded in the digital Julius Center CME platform. The full content of the module will be made available at the trial website (www.pimpomstudie.nl) after completion of the trial.

\section{Face-to-face meeting}

Upon completion of the online training module by GPs in the intervention primary care centre (PCC), a face-to-face meeting with the co-ordinating investigator and the GPs will be scheduled at the GP's PCC to ensure engagement. This also provides an opportunity to discuss the main topics of the online training module (see above and Table 1) and potential barriers and facilitators to analgesic prescription.

\section{Parent information leaflet}

The parent information leaflet is illustrated in Additional file 1; it explains the importance of adequate pain management and includes tables of weight-appropriate dosing of paracetamol and ibuprofen based on prevailing Dutch guidelines $[1,24]$. The leaflet also debunks common myths and misconceptions about the use of analgesics in children $[10,11]$.

\section{Prescription of analgesics}

Despite paracetamol and ibuprofen being available over-the-counter in the Netherlands, GPs in the intervention group are requested to prescribe these drugs at a 
Table 1 Main topics in the blended learning module

\begin{tabular}{|c|c|c|c|}
\hline Topic & Intervention element & Educational component & Educational level \\
\hline $\begin{array}{l}\text { Otoscopy, including abnormal tympanic membrane } \\
\text { appearances (AOM, OME) }\end{array}$ & $\begin{array}{l}\text { Online training module } \\
\text { (both intervention and control) }\end{array}$ & $\begin{array}{l}\text { Case-based learning } \\
\text { Self-assessment with } \\
\text { immediate feedback (MC) }\end{array}$ & $\begin{array}{l}\text { Knowledge } \\
\text { Skills }\end{array}$ \\
\hline Prevalence and natural course of earache due to $\mathrm{AOM}$ & Online training module & $\begin{array}{l}\text { Case-based learning } \\
\text { Self-assessment with } \\
\text { immediate feedback (MC) }\end{array}$ & Knowledge \\
\hline (Limited) effect of antibiotics on AOM symptoms, including earache & Online training module & $\begin{array}{l}\text { Case-based learning } \\
\text { Self-assessment with } \\
\text { immediate feedback (MC) }\end{array}$ & Knowledge \\
\hline Safety and adverse effects of paracetamol and ibuprofen & Online training module & $\begin{array}{l}\text { Case-based learning } \\
\text { Self-assessment with } \\
\text { immediate feedback (MC) }\end{array}$ & Knowledge \\
\hline $\begin{array}{l}\text { Parents' beliefs, concerns, and expectations relating to } \\
\text { (earache due to) AOM and analgesics use }\end{array}$ & $\begin{array}{l}\text { Online training module } \\
\text { Face-to-face training }\end{array}$ & $\begin{array}{l}\text { Case-based learning } \\
\text { Open questions }\end{array}$ & Knowledge \\
\hline GP barriers to prescribe paracetamol and/or ibuprofen & $\begin{array}{l}\text { Online training module } \\
\text { Face-to-face training }\end{array}$ & Open questions & $\begin{array}{l}\text { Knowledge } \\
\text { Attitude }\end{array}$ \\
\hline $\begin{array}{l}\text { Dosing and timing of analgesics according to the } 2007 \text { "Pain Relief" } \\
\text { guideline [24] (and subsequent } 2014 \text { "AOM in children" guideline [1]) }\end{array}$ & $\begin{array}{l}\text { Online training module } \\
\text { Face-to-face training } \\
\text { Information leaflet }\end{array}$ & $\begin{array}{l}\text { Case-based learning } \\
\text { Self-assessment with } \\
\text { immediate feedback (MC) }\end{array}$ & $\begin{array}{l}\text { Knowledge } \\
\text { Skills }\end{array}$ \\
\hline $\begin{array}{l}\text { How to use effective communication skills to address pain } \\
\text { management in a consultation }\end{array}$ & Online training module & Video demonstration & Skills \\
\hline $\begin{array}{l}\text { Use the three communication elements of an effective } \\
\text { consultation }[13,21] \text { : } \\
\text { - explore beliefs, concerns and expectations of parents regarding } \\
\text { the use of analgesia } \\
\text { - stress the importance of analgesic treatment during the consultations } \\
\text { and agree with the parents on pain management } \\
\text { - check parents' understanding }\end{array}$ & Online training module & Video demonstration & $\begin{array}{l}\text { Behaviour } \\
\text { Attitude }\end{array}$ \\
\hline Use a parent information leaflet during the consultation & $\begin{array}{l}\text { Face-to-face training } \\
\text { Information leaflet }\end{array}$ & Lecture/presentation & $\begin{array}{l}\text { Behaviour } \\
\text { Attitude }\end{array}$ \\
\hline Prescribe paracetamol and ibuprofen & $\begin{array}{l}\text { Face-to-face training } \\
\text { Information leaflet }\end{array}$ & Lecture/presentation & $\begin{array}{l}\text { Behaviour } \\
\text { Attitude }\end{array}$ \\
\hline
\end{tabular}

AOM acute otitis media, GP general practitioner, $M C$ multiple choice, $O M E$ otitis media with effusion

weight-appropriate dose $[1,24]$ and request parents to fill these prescriptions at the local pharmacy the same day.

\section{Randomised controlled trial of the intervention to optimise pain management in children with AOM \\ Study design and setting}

We designed a pragmatic, cluster randomised controlled trial to assess the clinical and cost effectiveness of the primary-care based multifaceted educational intervention aimed at optimising pain management compared with 'care as usual' in children with AOM. A SPIRIT checklist is attached as Additional file 2, and the SPIRIT figure (Fig. 1) shows the study design.

Approximately 30 general practices in multiple regions across the Netherlands will participate and enrol children to the trial. The trial recruitment period is 3 years with a follow-up of individuals for 4 weeks. Participating PCCs will be revisited every year in the autumn (prior to the annual peak incidence of AOM) to refresh key elements of the intervention and study procedures.

\section{Randomisation and blinding}

The unit of randomisation is the PCC; participating centres are randomly allocated to either the multifaceted education intervention or the usual care group. GPs in the same PCC will thus be allocated to the same 'treatment' group to avoid contamination issues.

A trial website has been designed to randomly assign participating PCCs to either the intervention or the control group. To ensure equal distribution of PCC characteristics (size and age distribution) across 'treatment' groups, an independent statistician has designed a computerised minimisation strategy with a random component of 30\% [25].

We will perform an open-label trial, in other words no blinding will be performed. However, to avoid contamination between intervention and control PCCs during enrolment as much as possible, GPs in the control group are asked to participate in a study to monitor earache in children with AOM. 


\begin{tabular}{|c|c|c|c|c|c|c|}
\hline \multirow[t]{2}{*}{ Timepoint } & \multirow[t]{2}{*}{ Prior to inclusion } & \multirow[t]{2}{*}{ Enrolment } & \multicolumn{3}{|c|}{ Individual patient follow-up } & \multirow[t]{2}{*}{ Close-out } \\
\hline & & & $\begin{array}{l}\text { Parent-reported } \\
\text { symptom diary }\end{array}$ & Phone call & $\begin{array}{l}\text { Medical file } \\
\text { extraction }\end{array}$ & \\
\hline & & Day 0 & Day $0-28$, daily & Day 3 & Day 28 & \\
\hline \multicolumn{7}{|l|}{ CLUSTER RANDOMISED INTERVENTION } \\
\hline Informed consent PCCs & $\mathrm{x}$ & & & & & \\
\hline Randomisation & $\mathrm{x}$ & & & & & \\
\hline $\begin{array}{l}\text { Educational intervention to optimise pain management } \\
\text { for GPs in intervention PCCs }\end{array}$ & $\mathbf{x}$ & & & & & \\
\hline Diagnostic module for all GPs & $\mathrm{x}$ & & & & & \\
\hline \multicolumn{7}{|l|}{ ENROLMENT AT PCCs } \\
\hline Screen for eligibility & & $\mathrm{x}$ & & & & \\
\hline Informed consent individual patients & & $\mathrm{x}$ & & & & \\
\hline Patient inclusion form completed & & $x$ & & & & \\
\hline \multicolumn{7}{|l|}{ ASSESSMENT } \\
\hline \multicolumn{2}{|l|}{ Baseline data $^{1}$} & $\mathrm{x}$ & $\mathrm{x}$ & & $\mathrm{x}$ & \\
\hline \multicolumn{2}{|l|}{ AOM-related symptoms ${ }^{2}$} & & $\mathrm{x}$ & $\mathrm{x}$ & & \\
\hline \multicolumn{2}{|l|}{ AOM-related symptoms prior to GP visit } & & $x$ & & & \\
\hline \multicolumn{2}{|l|}{ Otoscopic findings } & $\mathrm{x}$ & & & $\mathrm{x}$ & \\
\hline \multicolumn{2}{|l|}{ Mean earache at day 1-3 } & & $\mathrm{x}$ & $\mathrm{x}$ & & \\
\hline \multicolumn{2}{|l|}{ 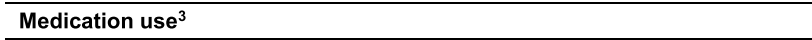 } & & $x$ & $\mathrm{x}$ & $\mathrm{x}$ & \\
\hline \multicolumn{2}{|l|}{ OM-related quality of life } & & $\mathrm{x}$ & & & \\
\hline \multicolumn{2}{|l|}{ Productivity loss ${ }^{4}$} & & $\mathrm{x}$ & & & \\
\hline \multicolumn{2}{|l|}{ Adverse events $^{5}$} & & & & $\mathrm{x}$ & \\
\hline \multicolumn{2}{|l|}{ GP reconsultation ${ }^{6}$} & & & & $\mathrm{x}$ & \\
\hline $\begin{array}{l}\text { Evaluation according to Kirckpatrick's model } \\
: \quad \text { Online module } \\
: \quad \text { Plended learning } \\
: \quad \text { Prent information leaflet } \\
\text { - } \quad \text { Combined intervention }\end{array}$ & $\mathbf{x}$ & & $\begin{array}{l}x \\
X \\
x\end{array}$ & & & $\mathbf{x}$ \\
\hline \multicolumn{7}{|c|}{$\begin{array}{l}\text { Baseline data includes age, gender, medical history, day-care attendance, vaccination status, exposure to tobacco smoke, family composition, items discussed } \\
\text { by GP during AOM consultation } \\
{ }^{2} \text { Symptoms include earache (on Wong-Baker Faces Scale rating), ear discharge, fever, runny nose, cough, disturbed sleep, diarrhoea, obstipation, vomiting, de- } \\
\text { creased fluid intake, abdominal pain, and rash. } \\
{ }^{3} \text { Medication use includes specification of type of medication, dosing frequency, actual dosage given, over-the-counter medication, (delayed) antibiotic prescription) } \\
{ }^{4} \text { Productivity loss is captured as composite of: number of days absence from work (parent) or day-care (child), number of hours a nanny was required, costs of } \\
\text { nanny employment. } \\
{ }^{5} \text { Adverse events include gastro-intestinal complaints, as well as serious adverse events such as renal failure, gastrointestinal bleeding, and hypersensitivity reac- } \\
\text { tions } \\
6 \text { GP reconsultation includes out-of-hours consultation and referral to secondary care (i.e. ER visits, hospital admissions, surgical procedures). }\end{array}$} \\
\hline \multicolumn{7}{|c|}{$\begin{array}{l}\text { Fig. } 1 \text { Overview and schedule of enrolment, data collection, and assessments (SPIRIT Figure). }{ }^{1} \text { Baseline data includes age, gender, medical history, } \\
\text { day-care attendance, vaccination status, exposure to tobacco smoke, family composition, and items discussed by general practitioner (GP) during } \\
\text { acute otitis media (AOM) consultation. }{ }^{2} \text { Symptoms include earache (on Wong-Baker Faces Scale rating), ear discharge, fever, runny nose, cough, } \\
\text { disturbed sleep, diarrhoea, obstipation, vomiting, decreased fluid intake, abdominal pain, and rash. }{ }^{3} \text { Medication use includes specification of type } \\
\text { of medication, dosing frequency, actual dosage given, over-the-counter medication, (delayed) antibiotic prescription. }{ }^{4} \text { Productivity loss is captured } \\
\text { as composite of number of days absence from work (parent) or day-care (child), number of hours a nanny was required, and costs of nanny } \\
\text { employment. }{ }^{5} \text { Adverse events include gastrointestinal complaints, as well as serious adverse events such as renal failure, gastrointestinal bleeding, } \\
\text { and hypersensitivity reactions. }{ }^{6} \mathrm{GP} \text { re-consultation includes out-of-hours consultation and referral to secondary care (i.e. emergency room visits, } \\
\text { hospital admissions, and surgical procedures). PCC primary care centre }\end{array}$} \\
\hline
\end{tabular}

To ensure standardised AOM diagnosis, each participating GP receives unique user credentials to access the digital Julius Center CME platform containing an online module illustrating various otoscopic images (i.e. normal appearance of tympanic membrane, AOM, and otitis media with effusion). GPs in the intervention PCCs receive additional access to the online training module.

\section{Eligibility criteria}

Children aged 6 months to 10 years presenting to their GP with earache and AOM are eligible for inclusion. Those with ventilation tubes in place are excluded, as well as previously included children, those with a previously included sibling, and children with either Down's syndrome, craniofacial malformations, known immunodeficiencies, liver failure, or renal insufficiency.

\section{Inclusion and baseline assessments}

All participating GPs inform the parents of potentially eligible children about the trial. After obtaining informed consent, GPs complete a short questionnaire regarding the child's medical history (recurrent AOM, recurrent upper respiratory tract infection, previous ENT surgery, and atopy) and perform a short physical examination (presence of fever and appearance of the tympanic membrane).

Participating GPs are also asked to complete non-recruitment logs, documenting reasons for 
non-recruitment of eligible patients and eligible patients who declined to participate.

GPs in the intervention group will advise parents of children on analgesics according to the instructions of the multifaceted intervention (see above). Other clinical decisions such as antibiotic prescriptions are at the discretion of the GP. Children in the control group will receive 'care as usual' and complete the same study procedures as those in the intervention group.

\section{Follow-up data collection}

At inclusion, GPs provide parents with a study diary to report various outcomes (see Fig. 1). Parents complete a daily symptom diary for 2 consecutive weeks. At baseline, and at 2 and 4 weeks, parents complete quality of life questionnaires and, at 4 weeks, parents fill out a productivity loss questionnaire. The study team will contact parents by phone on day 3 to optimise parents' compliance and to capture critical data on our primary outcome (Fig. 1). One month after inclusion, the co-ordinating investigator will contact parents by telephone or email with a reminder to return the completed diary by mail.

After 4 weeks, the coordinating investigator will visit the PCC to retrieve the data of participating children from their medical records (Fig. 1).

\section{Validated questionnaires used}

Parents report their child's earache intensity using the Wong-Baker FACES ${ }^{\circ}$ Pain Rating Scale (scores range from 0 to 10, with lower scores indicating less pain) [26-29]. Disease-specific quality of life of the child is assessed at baseline and at 4 weeks with the parent-reported Otitis Media-6 (OM-6), a six-item questionnaire recording ear-related problems (scores range from 6 to 42, with lower scores indicating better quality of life) [30]. Quality of life of the parents is assessed at baseline and at 2 weeks with the EuroQOL five dimensions quality of life questionnaire (EQ-5D) [31], and productivity losses are assessed with an adapted version of the iMTA Productivity Cost Questionnaire (iPCQ) [32].

\section{Primary and secondary outcomes}

The primary outcome of interest is the difference in parent-reported mean earache score over the first 3 days. Secondary outcomes are the number of days with earache and earache severity, number of days with fever, the proportion of children with earache at various time points ( 24 h, 2 to 3 days, 4 to 7 days), GP re-consultation because of AOM, antibiotic prescriptions because of AOM, health-related quality of life (HRQoL) of the child and their parents, working days lost for the parents, days lost from day-care or school for children, complications of AOM, (serious) adverse events of analgesics, healthcare use, and cost effectiveness.

\section{Sample size calculation}

In a previous childhood AOM trial, the mean earache score on days 1 to 3 was 3.7 (standard deviation 2.57) [33]. We consider a $25 \%$ reduction of this mean earache score clinically relevant. With $80 \%$ power, at a $5 \%$ significance level, a minimum of 66 children per group is needed. The inflation factor for the cluster design is 1.7 assuming an intra-class correlation coefficient of 0.05 (for PCC level) [34, 35] and a cluster size of 15 children (anticipating that not all PCCs recruit children to the trial). As such, the number of children that need to be included per group will be 115 . Based on previous experience, we consider a loss to follow-up of $10 \%$ to be reasonable [36, 37], and therefore aim to include 125 children per group ( 250 children in total).

\section{Statistical analysis}

Analysis will be performed according to the intention -to-treat principle.

Clinical effectiveness For our primary outcome, we will calculate the effect of the multifaceted intervention on parent-reported mean earache score over the first 3 days using a linear mixed model. A random intercept for PCC will be included in the model to account for cluster randomisation and a residual covariance (i.e. generalised estimating equation type) matrix will be included for repeated measurements (days 1,2, and 3 after the initial GP visit). Clustering is estimated with an intra-class correlation. Treatment effects will be reported as the crude and adjusted difference in mean earache scores over the first 3 days between study groups with accompanying 95\% confidence intervals. We plan to adjust for baseline differences in pre-specified confounders [38], including age, gender, ill appearance, fever, history of recurrent AOM, antibiotic use, and day-care attendance. Missing data at baseline will be imputed using the multivariate imputation by chained equations (MICE) procedure [39]. The imputed data sets will be analysed, and results combined. We will average estimates of the treatment effects to give a single mean estimate and adjusted standard errors according to Rubin's rule [40]. In primary analysis, we will include all patients for whom the outcome was observed. In a sensitivity analysis, or in case of extensive missing data, we will impute missing outcome data using the multiple imputation techniques described above [41]. Where appropriate, we will also perform an adherence-adjusted analysis.

For our secondary outcomes, we will use mixed logistic regression analyses for dichotomous variables, and mixed Poisson regression analyses for count variables. In case of insufficient or non-events, for example very few re-consultations, we will perform a simplified analysis without adjustment for confounders and clustering. 
Cost-effectiveness analysis (CEA) We will take medical and non-medical direct and indirect costs into account, thus using a societal perspective for this analysis. All analyses will use a time horizon of 4 weeks, corresponding to the follow-up period in the study. Therefore, discounting is not applicable.

We will use a Dutch database of current drug prices (www.medicijnkosten.nl) to estimate costs of patient drug use. These costs will be increased with a pharmacist's charge. We will base the costs of over-the-counter medication and complementary medication, if used, on average retail prices. We will base the costs of consulting a GP or a medical specialist, or other procedures and hospitalisations, on current Dutch guidelines for pharmaco-economic evaluation [42]. These guidelines include reference cost figures for use in health economic evaluations for common types of healthcare use. We extract resource use from the patient diaries. This includes doctor visits, prescribed medication including antibiotics, specialist referrals, hospital admissions, and surgical interventions, as well as out-of-pocket expenses such as over-the-counter medication, child care, and travel costs. When no reference prices are available, we will calculate cost prices according to guidelines for economic evaluation in healthcare research [42]. Indirect costs to society associated with absence from work will be estimated using the friction cost method [43]. Overall costs will be compared across the study groups and, where relevant, we will calculate differences, including 95\% confidence intervals, using two-stage non-parametric bootstrap sampling (of clusters and participants) [44].

In cost-effectiveness analysis, we will calculate incremental cost-effectiveness ratios by dividing the estimated differences in costs by the differences in effects observed, i.e. the additional cost per point reduction in mean earache score on days 1 to 3 , for the optimised pain management strategy compared with the 'usual care' strategy.

We will address uncertainty by means of two-stage non-parametric bootstrap sampling (of clusters and participants) [44]. We will use net benefit regression methods to study the effect of any differences in baseline characteristics and cluster differences on cost-effectiveness results. We will compare the results of the two-stage bootstrap sampling and the multilevel net benefit regression methods to assess robustness of the cost-effectiveness estimates. We will present the final results using incremental cost-effectiveness planes and cost-effectiveness acceptability curves.

\section{Process evaluation: understanding change processes}

During the recruitment phase, we will perform two qualitative studies as process evaluations alongside our trial to unravel mechanisms by which the multifaceted intervention may sort its effects [45-47]. In both studies we will use semi-structured interviews, which are audio-recorded and transcribed verbatim. Interviews will be analysed thematically using a grounded theory approach by all members of the multidisciplinary research team, including a primary healthcare sociologist, an ENT surgeon, an educational specialist, and academic GPs. We expect to reach saturation after 10-20 interviews in each study based on previous research [11, 48].

In one qualitative study, we will interview a subset of GPs in the intervention PCCs using purposeful sampling. In these interviews, the views and expectations of GPs on analgesia and how the multifaceted educational intervention shaped these perceptions will be explored. In a second qualitative study, we will perform interviews with parents from both the intervention and control groups to investigate their perceptions towards earache, AOM, and its management (with a specific focus on analgesia), and their experiences with AOM-related doctor consultations in general and the baseline study visit in particular. The results of these process evaluations will facilitate the interpretation of trial results. We also plan to conduct a further evaluation according to Kirkpatrick's evaluation model [49] (see Table 2) which may aid future implementation of the intervention.

\section{Implementation of the multifaceted intervention}

The results of this research project will be disseminated through publications in peer-reviewed professional journals, and will be presented at national and international conferences. If our intervention proves effective, we will liaise with all relevant stakeholders including GPs, parents

Table 2 Evaluation of the intervention according to Kirkpatrick's model

\begin{tabular}{lll}
\hline Intervention & Evaluation method & Evaluated aspect \\
\hline Online module & Audio-recorded evaluation during the face-to-face visit with the coordinating investigator & Reaction/satisfaction \\
Blended learning & $\begin{array}{l}\text { Questionnaire at baseline in the parental diary assessing whether analgesic treatment } \\
\text { was explicitly discussed during the consultation }\end{array}$ & Knowledge/behaviour \\
Parent information & $\begin{array}{l}\text { Questionnaire at baseline in the parental diary assessing whether the leaflet } \\
\text { leaflet }\end{array}$ & $\begin{array}{l}\text { Knowledge/behaviour } \\
\text { - has been discussed during the consultation }\end{array}$ \\
Prescription & Questionnaire at baseline in the parental diary assessing whether the general & Reaction/satisfaction \\
practitioner prescribed paracetamol and/or ibuprofen & Knowledge/behaviour \\
\hline
\end{tabular}


of children with AOM, and the Dutch College of General Practitioners (Nederlands Huisartsen Genootschap) to develop a dissemination and implementation plan to ensure rapid and effective dissemination and translation into clinical practice.

\section{Data management}

\section{Data monitoring}

Although monitoring is not strictly necessary in the Netherlands for studies to which the Dutch Medical Research Involving Human Subjects Act (WMO) does not apply, we will have our study monitored yearly by an independent Data Monitoring Committee at the University Medical Center Utrecht, in the shape of a low-risk research data monitor, to ensure the quality of the trial execution.

\section{Data deposition and curation}

Each participant is assigned a unique study identification number. This enables us to handle and store data in a non-traceable manner within a secured and coded database designed by the data management department of the Julius Center. Paper-based data are automatically entered on an online database (Research Online) which our data management department develops and maintains. After termination of the study, the database will become available to authorised persons (investigators, monitors, auditors) only. We have not planned any interim analyses.

Upon completion of the trial, data are stored for the at least 15 years on a central drive of the data management department of the Julius Center and will be made available for the use by third parties upon request and approval of the principal investigator (RAMJD).

\section{Discussion}

To our knowledge, this trial is unique in focusing on optimising analgesia to reduce pain and antibiotic use in childhood acute otitis media. The trial intervention has been developed systematically in close collaboration with educational and clinical experts and parents of children with AOM. The trial will assess both clinical and cost effectiveness, as well as underlying mechanisms through parallel process evaluations.

Even though the intervention is targeted at GPs, the impact is measured at the patient level which potentially underestimates the benefit of optimising pain management. However, we deem an individually randomised, placebo-controlled trial unethical since analgesics are widely accepted as standard care in children with AOM.

Findings from the trial and parallel process evaluations may contribute to optimisation of childhood AOM management.

\section{Trial status}

The trial design has been registered prior to enrolment on 19 December 2014 in a public trial registry (Netherlands Trial Register, NTR4920). At the time of submission of this manuscript, 218 patients have been recruited into the trial.

\section{Additional file}

Additional file 1: Information leaflet about pain relief for children with middle ear infection. (PDF $665 \mathrm{~kb}$ )

Additional file 2: SPIRIT 2013 checklist: recommended items to address in a clinical trial protocol and related documents. (DOC $120 \mathrm{~kb}$ )

\begin{abstract}
Abbreviations
AOM: Acute otitis media; ENT: Ear, nose, and throat; EQ-5D: EuroQol five dimensions quality of life questionnaire; GP: General practitioner; HRQoL: Health-related quality of life; iPCQ: iMTA Productivity Cost Questionnaire; OM-6: Otitis Media-6; PCC: Primary care centre; WMO: Dutch Medical Research Involving Human Subjects Act
\end{abstract}

\section{Acknowledgements}

The authors would like to thank Liesbeth Rijnierse for her assistance in information leaflet translation.

\section{Funding}

The trial was supported by a grant from the Netherlands Organisation for Health Research and Development (ZonMw) - HGOG subprogramme (project number 839110005). The funders had no role in the study design, data collection and analysis, decision to publish, or preparation of the manuscript.

\section{Availability of data and materials}

Data sharing is not applicable to this article as no datasets were generated or analysed during the current study.

\section{Safety considerations}

The use of paracetamol and ibuprofen in children has been proven to be safe; both safety and tolerability of paracetamol are equal to placebo [50], and the risk-profile of ibuprofen is similar to paracetamol [51]. We will collect data on (serious) adverse events during follow-up (see Fig. 1), and management of any events is at the discretion of the GP. We have not installed a data safety monitoring board nor planned any interim analyses.

\section{Authors' contributions}

RPV, AGMS, and RAMJD conceptualised and designed the trial and acquired funding. AS and ACvdP drafted the first version of the protocol, and RPV, AGMS, and RAMJD provided feedback on this version. All authors approved the final version of the protocol. RTVU and RPV drafted the first version of the manuscript, and AS, ACvdP, GAdW, AGMS, and RAMJD provided feedback on the manuscript. All authors read and approved the final version of the manuscript.

\section{Ethics approval and consent to participate}

The trial is conducted according to the principles of the Declaration of Helsinki (10th version, October 2013) [52] and the Dutch Conduct Code Health Research (Gedragscode Gezondheidsonderzoek "Goed Gedrag") [53]. The Medical Ethics Review Committee of the University Medical Center Utrecht, the Netherlands, reviewed the study protocol (protocol WAG/om/ 14/021633) and confirmed that an official approval was not required since the Medical Research Involving Human Subjects Act (WMO) does not apply to our trial since participation in the study does not add to the risks inherent to the condition (AOM) and its management in Dutch primary care.

Consent for publication

Not applicable. 


\section{Competing interests}

The authors declare that they have no competing interests.

\section{Publisher's Note}

Springer Nature remains neutral with regard to jurisdictional claims in published maps and institutional affiliations.

\section{Author details}

'Julius Center for Health Sciences and Primary Care, University Medical Center Utrecht, Utrecht University, Stratenum 5.143, PO Box 85500, 3508, GA, Utrecht, The Netherlands. ${ }^{2}$ Centre for Nutrition, Prevention and Healthcare, National Institute of Public Health and the Environment, Bilthoven, The Netherlands. ${ }^{3}$ evidENT, Ear Institute, University College London, London, UK.

\section{Received: 23 March 2018 Accepted: 27 August 2018}

\section{Published online: 17 September 2018}

\section{References}

1. Damoiseaux RAMJ, Venekamp RP, Eekhof JAH, Bennebroek Gravenhorst FM, Schoch AG, Wittenberg J, et al. NHG-standaard Otitis media acuta bij kinderen. Huisarts Wet. 2014;57(12):648 Available through: https://www.nhg. org/standaarden/volledig/nhg-standaard-otitis-media-acuta-bij-kinderen.

2. Lieberthal AS, Carroll AE, Chonmaitree T, Ganiats TG, Hoberman A, Tunkel $\mathrm{DE}$, et al. The diagnosis and management of acute otitis media. Pediatrics. 2013;131(3):e964-99.

3. Coco A, Vernacchio L, Horst M, Anderson A. Management of acute otitis media after publication of the 2004 AAP and AAFP clinical practice guideline. Pediatrics. 2010;125(2):214-20.

4. Forrest CB, Fiks AG, Bailey LC, Localio R, Grundmeier RW, Alessandrini AE, Improving adherence to otitis media guidelines with clinical decision support and physician feedback. Pediatrics. 2013;131:e1071-81.

5. Pulkki J, Huikko S, Rautakorpi U-M, Honkanen P, Klaukka T, Mäkelä M, et al. Management of pain in acute otitis media in Finnish primary care. Scand Infect Dis. 2006;38(4):265-7

6. Tähtinen PA, Boonacker CWB, Rovers MM, Schilder AGM, Huovinen P, Ruohola A, et al. Parental experiences and attitudes regarding the management of acute otitis media-a comparative questionnaire between Finland and the Netherlands. Fam Pract. 2009;26:488-92.

7. Thompson PL, Gilbert LE, Long PF, Saxena S, Sharland M, Wong ICK. Has UK guidance affected general practitioner antibiotic prescribing for otitis media in children? J Public Health. 2008:30(4):479-86.

8. Tyrstrup M, Beckman A, Mölstad S, Engström S, Lannering C, Hedin K, et al. Reduction in antibiotic prescribing for respiratory tract infections in Swedish primary care-a retrospective study of electronic patient records. BMC Infect Dis. 2016;16:709

9. Cabral C, Lucas PJ, Ingram J, Hay AD, Horwoord J. "It's safer to..." parent consulting and clinician antibiotic prescribing decisions for children with respiratory tract infections: an analysis across four qualitative studies. Soc Science Med. 2015;136-137:156-64.

10. Lucas PJ, Cabral C, Hay AD, Horwood J. A systematic review of parent and clinician views and perceptions that influence prescribing decisions in relation to acute childhood infections in primary care. Scand J Prim Health Care. 2015;33(1):11-20.

11. Hansen MP, Howlett J, Del Mar C, Hoffmann TC. Parents' beliefs and knowledge about the management of acute otitis media: a qualitative study. BMC Fam Pract. 2015;16(1):82. https://doi.org/10. 1186/s12875-015-0297-7.

12. Baker R, Camosso-Stefinovic J, Gillies C, et al. Tailored interventions to overcome identified barriers to change: effects on professional practice and health care outcomes. Cochrane Database Syst Rev. 2014;3:CD005470. https://doi.org/10.1002/14651858.CD005470.pub2.

13. Butler CC, Simpson SA, Evans J, Moore L. Effectiveness of multifaceted educational programme to reduce antibiotic dispensing in primary care: practice-based randomised controlled trial. BMJ. 2012;344:d8173.

14. Tonkin-crine S, Yardley L, Coenen S, Fernandez-vandellos P, Krawczyk J, Touboul $\mathrm{P}$, et al. Strategies to promote prudent antibiotic use: exploring the views of professionals who develop and implement guidelines and interventions. Fam Pract. 2013;30(1):88-95.

15. Craig P, Dieppe P, Macintyre S, Michie S, Nazareth I, Petticrew M. Developing and evaluating complex interventions: the new Medica Research Council guidance. BMJ. 2008;337:a1655.
16. Davis DA, Thomson MA, Oxman AD, Haynes RB. Changing physician performance. A systematic review of the effect of continuing medical education strategies. JAMA. 1995;274(9):700-5.

17. Grimshaw JM, Thomas RE, MacLennan G, Fraser C, Ramsay CR, Vale L, et al. Effectiveness and efficiency of guideline dissemination and implementation strategies. Health Technol Assess. 2004;8(6):iii-v 1-72.

18. Fordis M, King JE, Ballantyne CM, Jones PH, Schneider KH, Greisinger AJ, et al. Comparison of the instructional efficacy of internet-based CME with live interactive CME workshops. JAMA. 2005;294(9):1043-51.

19. O'Brien MA, Rogers $S$, Jamtvedt G, Oxman AD, Odgaard-Jensen J, Kristoffersen DT, et al. Educational outreach visits: effects on professional practice and health care outcomes. Cochrane Database Syst Rev. 2007;4 CD000409. https://doi.org/10.1002/14651858.CD000409.pub2.

20. De Bont EGPM, Alink M, Falkenberg FCJ, Dinant GJ, Cals JWL. Patient information leaflets to reduce antibiotic use and reconsultation rates in general practice: a systematic review. BMJ Open. 2015;5:e007612.

21. McWilliams DB, Jacobson RM, van Houten HK, Naessens JM, Ytterberg KL. A program of anticipatory guidance for the prevention of emergency department visits for ear pain. Arch Pediatr Adolesc Med. 2008:162(2):151-6.

22. Cook DA, Dupras DM. A practical guide to developing effective web-based learning. J Gen Intern Med. 2004;19:698-707.

23. Little P, Stuart B, Francis N, Douglas E, Tonkin-Crine S, Yardley L, et al. Effects of internet-based training on antibiotic prescribing rates for acute respiratory-tract infections: a multinational, cluster, randomised, factorial, controlled trial. Lancet. 2013:382(9899):1175-82.

24. Verduijn MM, Folmer H. Farmacotherapeutische richtlijn Pijnbestrijding. Huisarts Wet. 2007:50:601-15.

25. Altman DG, Bland JM. Treatment allocation by minimization. BMJ. 2005;330:843.

26. Tomlinson D, von Baeyer CL, Stinson JN, Sung L. A systematic review of faces scales for the self-report of pain intensity in children. Pediatrics. 2010; 126(5):e1 168-98

27. Garra G, Singer AJ, Taira BR, Chohan J, Cardoz H, Chisena E, et al. Validation of the Wong-Baker FACES pain rating scale in pediatric emergency department patients. Acad Emerg Med. 2010;17(1):50-4.

28. Chambers CT, Hardial J, Craig KD, Court C, Montgomery C. Faces scales for the measurement of postoperative pain intensity in children following minor surgery. Clin J Pain. 2005;21(3):277-85.

29. Chambers CT, Giesbrecht K, Craig KD, Bennett SM, Huntsman E. A comparison of faces scales for the measurement of pediatric pain: children's and parents' ratings. Pain. 1999;83(1):25-35.

30. Rosenfeld RM, Goldsmith AJ, Tetlus L. Quality of life for children with otitis media. Arch Otolaryngol Head Neck Surg. 1997;123(10):1049-54.

31. Brooks R. EuroQol: the current state of play. Health Policy. 1996;37(1):53-72.

32. Bouwmans, et al. Handleiding iMTA Productivity Cost Questionnaire (iPCQ). Rotterdam: iMTA, Erasmus Universiteit; 2013. Available from: https://www. imta.nl/questionnaires/

33. Little P, Gould C, Williamson I, Moore M, Warner G, Dunleavey J. Pragmatic randomized controlled trial of two prescribing strategies for childhood acute otitis media. BMJ. 2001:322(7282):336-42.

34. McCarthy WF. Assessment of sample size and power for the analysis of clustered matched-pair data. Rockville: COBRA Preprint Series Working Paper 28, Maryland Medical Research Institute; 2007. Available from: https:// biostats.bepress.com/cobra/art28

35. Eldridge SM, Ashby D, Kerry S. Sample size for cluster randomized trials: effect of coefficient of variation of cluster size and analysis method. Int J Epidemiol. 2006;35:1292-300.

36. Damoiseaux RAMJ, Van Balen FAM, Hoes AW, Verheij TJM, De Melker RA. Primary care based randomised, double blind trial of amoxicillin versus placebo for acute otitis media in children aged under 2 years. BMJ. 2000; 320(7231):350-4

37. Venekamp RP, Bonten MJ, Rovers MM, Verheij TJ, Sachs AP. Systemic corticosteroid monotherapy for clinically diagnosed acute rhinosinusitis: a randomized controlled trial. CMAJ. 2012;184(14):E751-7.

38. Kahan $\mathrm{BC}$, Jairath $\mathrm{V}$, Doré $\mathrm{CJ}$, Morris TP. The risks and rewards of covariate adjustment in randomized trials: an assessment of 12 outcomes from 8 studies. Trials. 2014:15:139.

39. Donders AR, van der Heijden GJ, Stijnen T, Moons KG. Review: a gentle introduction to imputation of missing values. J Clin Epidemiol. 2006;59(10): 1087-91.

40. Rubin DB. Multiple imputation for non-response in surveys. New York: John Wiley; 1987 
41. Groenwold RHH, Moons KGM, Vandenbroucke JP. Randomized trials with missing outcome data: how to analyse and what to report. CMAJ. 2004; 186(15):1153-7.

42. Hakkaart-van Roijen $L$, van der Linden N, Bouwmans C, Kanters T, Tan SS, on behalf of Zorginstituut Nederland (Dutch National Health Institute). Kostenhandleiding - Methodologie van kostenonderzoek en referentieprijzen voor economische evaluaties in de gezondheidszorg. Diemen: 2016. Available through: https://www.zorginstituutnederland.nl/ binaries/zinl/documenten/publicatie/2016/02/29/richtlijn-voor-het-uitvoerenvan-economische-evaluaties-in-de-gezondheidszorg/Richtlijn+voor+het +uitvoeren+van+economische+evaluaties+in+de+gezondheidszorg +\%28verdiepingsmodules\%29.pdf. Accessed 19 June 2018.

43. Koopmanschap MA, Rutten FF, van Ineveld BM, van Roijen $L$, on behalf of the Institute for Medical Technology Assessment, Erasmus University, Rotterdam, The Netherlands. The friction cost method for measuring indirect costs of disease. J Health Econ. 1995;14(2):171-89.

44. Bachmann MO, Fairall L, Clark A, Mugford M. Methods for analyzing cost effectiveness data from cluster randomized trials. Cost Eff Resour Alloc 2007:6(5):12

45. Grant A, Treweek S, Dreischult T. Process evaluations for cluster-randomised trials of complex interventions: a proposed framework for design and reporting. Trials. 2013;14:15.

46. Jansen YFM, Foets MME, de Bont AA. The contribution of qualitative research to the development of tailor-made community-based interventions in primary care: a review. Eur J Publ Health. 2009;20(2):220-6.

47. Moore GF, Audrey S, Barker M, et al. Process evaluation of complex interventions: Medical Research Council guidance. BMJ. 2015;350:h1258.

48. Halcomb EJ, Furler JS, Hermiz OS, Blackberry ID, Smith JP, Richmond RL, et al. Process evaluation of a practice nurse-led smoking cessation trial in Australian general practice: views of general practitioners and practice nurses. Fam Pract. 2015;32(4):468-73.

49. Kirkpatrick DL. Techniques for evaluating training programs. Train Dev J. 1979;33:3-9.

50. Southey ER, Soares-Weiser K, Kleijnen J. Systematic review and meta-analysis of the clinical safety and tolerability of ibuprofen compared with paracetamol in paediatric pain and fever. Curr Med Res Opin. 2009;25(9):2207-22.

51. Pierce CA, Voss B. Efficacy and safety of ibuprofen and acetaminophen in children and adults: a meta-analysis and qualitative review. Ann Pharmacother. 2010:44(3):489-506.

52. World Medical Association. WMA Declaration of Helsinki-ethical principles for medical research involving human subjects. Fortaleza; 2013. Available through: https://www.wma.net/policies-post/wma-declaration-of-helsinkiethical-principles-for-medical-research-involving-human-subjects/. Accessed 19 June 2018

53. Stichting Federatie van Medisch Wetenschappelijke Vereniging (Dutch Federation of Biomedical Science Associations). Gedragscode Gezondheidsonderzoek (Dutch Conduct Code for Health Research). Rotterdam; 2005. Available through: https:/www.federa.org/sites/default/ files/bijlagen/coreon/gedragscode_gezondheidsonderzoek.pdf. Accessed 19 June 2018.

Ready to submit your research? Choose BMC and benefit from:

- fast, convenient online submission

- thorough peer review by experienced researchers in your field

- rapid publication on acceptance

- support for research data, including large and complex data types

- gold Open Access which fosters wider collaboration and increased citations

- maximum visibility for your research: over $100 \mathrm{M}$ website views per year

At BMC, research is always in progress.

Learn more biomedcentral.com/submissions 